\title{
Introduction to Selected Contributions from the 52nd US Rock Mechanics/Geomechanics Symposium Held in Seattle, Washington from June 17 to 20,2018
}

\author{
Richard A. Schultz ${ }^{1}$ (1) \\ Published online: 21 November 2019 \\ (c) Springer-Verlag GmbH Austria, part of Springer Nature 2019
}

This special issue of Rock Mechanics and Rock Engineering contains 23 papers that were invited contributions from the more than 400 papers presented at the 52nd US Rock Mechanics/Geomechanics Symposium that was held in Seattle, Washington from June 17 to 20, 2018. The symposium brought together professional scientists, engineers, and students from academia, industry, and government in the areas of civil, geological, mining, geophysical, geothermal, and petroleum engineering. This symposium is the premier annual event organized by the American Rock Mechanics Association (ARMA) and has become one of the most recognized and important venues for rock mechanics and geomechanics research worldwide.

The technical sessions provided exciting opportunities to present and discuss the newest fundamental findings and applications obtained through analytical and numerical modeling, laboratory experiments, and field-scale studies. One of the strengths of the symposium was its success in bringing together rock- and geo-mechanicists from a wide range of disciplines to focus on problems, potential solutions, and innovative applications that were recognized as critical and needed across the discipline.

The papers contained in this special issue were selected by the session chairs, disciplinary track leads, and others on the Technical Program Committee of the 52nd US Rock Mechanics/Geomechanics Symposium based on the quality of their technical content as well as the presentation and discussion of the paper during the symposium. All invited papers were expanded, rewritten, and then peer-reviewed again following the standard procedures of Rock Mechanics and Rock Engineering prior to publication in this special issue.

For the first time, several new papers were prepared specifically for this special issue based upon invited keynote presentations delivered at the symposium. These papers also underwent peer-review and joined the other notable contributions from civil, mining, and petroleum engineering geomechanics along with a suite of cross-disciplinary topics such as geohazards, induced seismicity, and key learnings gleaned from case studies.

This special issue would not have been possible without the dedication of the many subject-matter experts who graciously provided peer reviews of the submitted papers. Their work, and that of the authors themselves in writing and revising their papers, was all the more remarkable since it overlapped the timeframe for abstract and conference-paper review for the subsequent (2019) symposium. All deserve a heart-felt 'thank-you' for assisting with this special issue simultaneously with their work with the current year's symposium. Thanks are also extended to Dr. Giovanni Barla, Editor-in-Chief of Rock Mechanics and Rock Engineering, Dr. Mariacristina Bonini, Ms. Narmadha Purusothaman, and all of the journal staff who worked so tirelessly to produce this fine and timely special issue.

Publisher's Note Springer Nature remains neutral with regard to jurisdictional claims in published maps and institutional affiliations.
Richard A. Schultz

oriongeo@gmail.com

1 Orion Geomechanics LLC, Cypress, TX, USA 